ORIGINAL ARTICLE ARTIGO ORIGINAL

\section{Unmet needs in multiple myeloma in Brazil from physicians' perspective - barriers in quality of life and disease management}

\author{
Necessidades não atendidas em mieloma múltiplo \\ no Brasil sob a perspectiva de médicos - barreiras \\ na qualidade de vida e manejo da doença
}

Angelo Maiolino ${ }^{1,2}$, Jorge Vaz Pinto Neto ${ }^{3}$, Leonardo Gomes Teixeira Leite ${ }^{4}$ Fernanda Salles Seguro ${ }^{5}$, Walter Moisés Tobias Braga ${ }^{6}$, Karla Richter Zanella7,8, Jairo Jose do Nascimento Sobrinho9,10, Renato Watanabe de Oliveira ${ }^{11}$, Guilherme Silva Julian"11, Paula Yurie Tanaka ${ }^{12}$

DOI: 10.21115/JBES.v10.n2.p165-171

\begin{abstract}
Objective: There is an increasing trend of the overall survival rates of multiple myeloma (MM) patients over the years, increasing the necessity to improve their quality of life and attenuate unmet medical needs. Therefore, this study aims to explore and describe unmet medical needs and barriers in Brazilian MM patients, based on physicians' perspective. Methods: A questionnaire with 41 questions was developed to collect information regarding clinical characteristics, unmet medical needs and barriers for the diagnosis and treatment of MM in Brazil. After physicians' responses, a panel discussion with all the participants was had in order to collect additional data and validate physicians' responses. Results: Participants had a mean of 18 years of professional experience and attended to a mean of thirty MM patients per month. MM patients treated by these physicians had a median time of disease of 7.5 months when initiating treatment in the public sector, and 2.5 months in the private sector. In both systems, the majority of patients referred were from general practitioners. Peripheral neuropathy was the most common adverse event reported with higher impact on patients' adherence and QoL. Conclusion: There are several challenges as to unmet medical needs, especially when comparing the private and public healthcare systems in Brazil. According to physicians, providing access to basic diagnostic procedures and adopting educational measures for both physicians and patients would help to minimize barriers in the current scenario of MM management in Brazil.
\end{abstract}




\section{Palavras-chave:}

mieloma múltiplo, necessidades médicas não atendidas,

qualidade de vida

\section{RESUMO}

Objetivo: Existe uma tendência no aumento das taxas de sobrevida global de pacientes de mieloma múltiplo (MM) ao longo dos anos, aumentando a necessidade de melhorar sua qualidade de vida e atenuar as necessidades médicas não atendidas na área. Desta forma, o objetivo deste estudo é explorar e descrever as necessidades médicas não atendidas e as barreiras em pacientes brasileiros de MM, a partir da perspectiva de médicos. Métodos: Um questionário com 41 questões foi desenvolvido para coletar dados sobre as características clínicas, necessidades médicas não atendidas e barreiras no diagnóstico e tratamento de MM no Brasil. Depois de coletar a resposta dos médicos, uma discussão em forma de painel com todos os participantes foi realizada para coletar dados adicionais e validar as respostas do questionário. Resultados: Os participantes tinham, em média, 18 anos de experiência profissional, atendendo-se no total uma média de 30 pacientes de MM por mês. Os pacientes de MM atendidos por esses médicos no sistema público apresentam em média 7,5 meses de doença ao iniciar o tratamento, enquanto no sistema privado apresentavam 2,5 meses. Em ambos os sistemas, a maioria dos pacientes foi referenciada por clínicos gerais. Neuropatia periférica foi o evento adverso mais frequentemente reportado pelos médicos, com maior impacto na adesão ao tratamento e na qualidade de vida. Conclusão: Existem diversos desafios relativos às necessidades médicas não atendidas, especialmente ao comparar os sistemas público e privado no Brasil. De acordo com os participantes, o acesso aos procedimentos diagnósticos básicos e a adoção de medidas de educação médica e de pacientes minimizariam as barreiras importantes no cenário brasileiro atual.

\section{Introduction}

Multiple Myeloma (MM) is a hematological malignancy characterized by increased proliferation of plasma cells in the bone marrow, and production of monoclonal antibodies (Kyle and Rajkumar 2009). MM corresponds only to a small fraction of all cancers; yet it is the second most common hematological malignancy, representing approximately $10 \%$ of the cases globally (Rajkumar 2016). According to GLOBOCAN, it is estimated that more than 114,250 of new MM cases are diagnosed worldwide each year (GLOBOCAN 2012).

Studies have confirmed the continuous increase in the patients' overall survival rates since the 1970's (Kristinsson et al. 2007, Kumar et al. 2008, Spicka 2014), with significant increases in 5-year relative survival rates of Myeloma patients from approximately 25\% in 1975 to 49\% in 2011 (Torre et al. 2016). The improvement observed in overall survival (OS) rates is related to the development of new diagnostic procedures, treatment strategies and therapeutic options. For instance, the development of high-dose chemotherapy with stem-cell transplantation in the 1980's and the development of novel therapeutic agents have significantly increased OS in MM patients (Kumar et al. 2008, Larocca and Palumbo 2011).

Despite the advances in treatment, MM is still an incurable disease that affects patients' quality of life (QoL) and deteriorates their physical condition. With the improvement of OS, more attention should be paid to supporting patients, as they will face long-term disease-related complications that include management of disease-related symptoms and increased risk of infections, among others. However, few studies have investigated the unmet medical needs of MM patients and their QoL in a real-world setting. For instance, Jordan et al. observed high rates of severe and moderate symptoms and adverse events in MM patients, reducing their Global Health Status as well as physical and social functioning (Jordan et al. 2014). In addition, other factors may also influence the management of MM patients' unmet needs. As reviewed by Noopur Raje et al., studies showed a suboptimal compliance to guidelines by healthcare professionals (Raje et al. 2014). This may indicate that guidelines are not always applicable to a real clinical practice setting and healthcare professionals need to adapt according to restrictions imposed by their local healthcare system.

Therefore, this panel aims to explore the unmet medical needs for MM management and barriers for MM diagnosis, staging and treatment in Brazil, according to the physicians' perspective.

\section{Methods}

This panel discussion was based on a two-step approach: the filling of a questionnaire (survey) by onco-hematologist/hematologists and a discussion on the compiled results. They were developed to understand and describe unmet medical needs in MM diagnosis, treatment and other factors in Brazil, from the physician's perspective. Seven hematologists/onco-hematologists with vast experience in MM management and treatment were selected to participate in the study. They were from private and public institutions geographically spread across Brazil, representing the South, Southeast and Central-West regions, with patients from both public and private healthcare systems.

A questionnaire was sent to each physician to be completed according to his/her individual experience and perspectives. Subsequently, after evaluating the data obtained from all questionnaires, an in-person panel discussion with all seven 
participants was scheduled to validate their opinions and discuss the unmet medical needs in MM and possibilities of overcoming them. The survey results were presented to all physicians and discussed topic by topic.

\section{Questionnaire development}

A literature review on MM and MM relapse/refractory (MM) RR) profile and its barriers in diagnosis, staging, treatment, adverse events (AE), QoL and adherence was performed to identify the topics for the survey. The questionnaire, containing 35 multiple-choice and 12 open-ended questions, was divided into four main subjects:

- Physicians' characterization: experience time; mean of patients/month; healthcare system and institutions of work.

- Characterization of patients in public and private healthcare systems: percentage of patients on each healthcare system.

- Clinical factors to decide treatment: QoL, AEs profile, toxicity, adherence and oral therapy.

- Barriers: diagnosis, staging, treatment and hospitalization access.

The questionnaire with 47 questions was sent by electronic mail directly to physicians and it was answered within 15 days. No measures were taken regarding missing data or response rates.

\section{Panel Meeting}

The seven onco-hematologist/hematologists who responded to the questionnaire were invited to participate in a panel discussion, which took place two weeks after sending the questionnaire. A compilation of the responses was presented during the meeting, where participants were able to validate their responses, share their experiences and discuss the unmet medical needs and potential measures to be considered to overcome those barriers.

\section{Data analysis}

Data from the responses to the questionnaire were extracted, open-ended questions were categorized, and multiple-choice questions were ranked when applicable. Additional information from the panel meeting was also considered. Frequency analysis of all responses was performed to summarize results, with descriptive purposes only. All results are reported in percentage of respondents and include more than one possibility in several questions.

\section{Results \\ Participants' profile}

Seven physicians (five onco-hematologists and two hematologists) spread across three different regions in Brazil (South, Southeast and Middle West regions) responded to the ques- tionnaire and participated in the panel discussion. The mean time of experience in the area was 18 years, ranging from 10 to 30 years. Five participants reported working in both private and public healthcare systems; two participants reported working exclusively in one healthcare system, one in the private sector and the other in the public sector.

\section{Physicians' patients profile}

All the participants have experience in treating MM patients, with a mean of thirty patients per month (ranging from 6 to 42 patients per month). For physicians working in both healthcare systems, $54 \%$ of their patients were from the public healthcare system; the remaining $46 \%$ were from the private system. Regarding the referral of patients, the participants mentioned that more than a half of their patients from the public healthcare system are referred by general practitioners (51.7\%), followed by orthopedists (20.8\%), hematologists (8.3\%), oncologists (4.2\%) and others (15\%). In the private healthcare system, participants reported that patients are referred mainly by general practitioners (38.3\%), oncologists (21.7\%), orthopedists (18.4\%) and others (21.7\%). The participants reported that, at first diagnosis, $59.2 \%$ of patients from the public healthcare system are in Stage III, followed by 27.5\% in Stage II, $12.5 \%$ in Stage I and $0.8 \%$ in an unknown stage. In the private healthcare system, most patients were diagnosed at Stage II (40\%), followed by Stage III (35\%) and Stage I (25.8\%).

\section{Quality of Life}

All of the participants considered important the use of tools to determine the patients' QoL. Approximately $85 \%$ of the participants considered the use of QoL critical when choosing the therapy; $15 \%$ reported QoL is important, but do not use it to define therapy. All respondents consider that more QoL studies in MM patients and MM treatment should be developed. According to participants, time of diagnosis negatively affects $\mathrm{QoL}$ in both fit and unfit/frail patients, achieving a mean of $7.5 \pm 1.9$ and $6.8 \pm 2.5$, respectively, in importance scale ( $0=$ no impact, $10=$ high impact). In addition, $43 \%$ of the respondents reported using frailty scores in their institutions.

In fit patients, participants reported that improving symptoms and maintaining patients' habits/routine are the most important factors in QoL improvement, while in unfit/frail patients, improving symptoms and decreasing toxicity were described as more relevant in QoL improvement (Table 1).

\section{Public and Private Healthcare Section}

All participants responded to specific questions on MM profile as well as unmet needs in public and private healthcare. Six physicians responded regarding the public and private healthcare system, of which five work in both systems, one works exclusively in the private system and one exclusively in 
Table 1. The most important factors associated with the improvement of QoL during the treatment of Fit and Unfit/frail patients

\begin{tabular}{lcc}
\hline Rank & Fit & Unfit/frail \\
\hline 1 & Improvement of symptoms & Improvement of symptoms \\
\hline 2 & $\begin{array}{c}\text { Maintenance of routine / } \\
\text { daily activities of the patient }\end{array}$ & Minor toxicity \\
\hline 3 & Minor toxicity & $\begin{array}{c}\text { Maintenance of routine / } \\
\text { daily activities of the patient }\end{array}$ \\
\hline 4 & Emotional state of patient & Emotional state of patient \\
\hline
\end{tabular}

the public system. Therefore, for both the public and private healthcare, six participants will be considered 100\%.

\section{Treatment choice}

In the public healthcare system, the median time from disease detection to start of therapy was 7.5 months (3-12), while, in the private healthcare system, patients had a median of 2.5 (1-6) months. In the public healthcare system, physicians mentioned type of relapse (50\%), previous treatments (33.3\%), disease aggressiveness (33.3\%), progression-free survival (16.7\%), patient's comorbidities (16.7\%) and drugs available in the institution (16.7\%) as factors considered in therapy choice of MM/RR patients. In the private healthcare system, physicians mentioned type of relapse (50\%), disease aggressiveness (50\%), symptoms (14.2\%), previous AEs (14.2\%) and patient's comorbidities (14.2\%) as the factors influencing therapy choice of MM/RR.

\section{Adverse events profile}

Physicians reported peripheral neuropathy and asthenia as the most common AEs during treatment in the public healthcare system, and peripheral neuropathy and diarrhea in the private healthcare system (Table 2). Additionally, physicians also described peripheral neuropathy more frequently as the $A E$, with higher impact in patient's QoL and treatment adherence in both healthcare systems (Table 3). Also, participants most commonly described peripheral neuropathy as the most common AE impacting on treatment in MM/RR patients (Table 2)

\section{Impact of drug administration route in QoL and treatment adherence}

In the public and private healthcare systems, $83.3 \%$ and 80\% of the participants described that oral therapy in MM/RR treatment presents differences compared with intravenous therapy in QoL, of which the main differences are described in Table 4. According to participants, oral and intravenous therapies for MM/RR also present differences in treatment adherence in public (50\% of the respondents) and private healthcare systems (60\% of the respondents), whose main differences are described in (Table 5).

\section{Diagnosis, staging and treatment}

All participants described the use of bone marrow aspirate or bone marrow biopsy in both public and private healthcare systems. However, fewer participants reported these procedures for patient follow-up (33.3\% in public and $40 \%$ in private). Among imaging tests used in diagnosis, staging and patient follow-up, X-Ray and NMR were the most commonly used in both the public and private sectors (Table 6). Exclusively in the private healthcare system, $60 \%$ of the physicians use cytogenetic FISH in diagnosis.

Regarding hospitalization in MM/RR patients, physicians reported that from $15-25 \%$ of the patients from public healthcare need hospitalization, while, in the private sector, physicians described hospitalization as low, up to $10 \%$ of the patients. In the opinion of 50\% of the physicians, hospitalization access in the public sector is easy, while the other $50 \%$ claim that hospitalization may be a barrier due to a lack of proper access; in the private sector, $60 \%$ of the physicians claimed hospitalization to be easy.

Table 2. The most common adverse events during MM treatment and the adverse events that most impact treatment choice in both healthcare systems, based on the physicians' response rate

\begin{tabular}{lclcllcc}
\hline Most frequent AEs & & & \multicolumn{3}{l}{ AEs impacting treatment choice } \\
\hline Public & $\%$ & Private & $\%$ & Public & $\%$ & Private & \% \\
\hline Peripheral neuropathy & 83.3 & Peripheral neuropathy & 80 & Peripheral neuropathy & 66.7 & Peripheral neuropathy & 100 \\
\hline Asthenia & 50.0 & Diarrhea & 80 & Renal insufficiency & 50.0 & Febrile neutropenia & 40 \\
\hline Infection & 50.0 & Anemia & 40 & Infection & 50.0 & Infection & 40 \\
\hline Thrombocytopenia & 33.3 & Thrombocytopenia & 40 & Afebrile neutropenia & 33.3 & Anemia & 20 \\
\hline Renal insufficiency & 33.3 & Asthenia & 40 & Diarrhea & 33.3 & Thrombocytopenia & 20 \\
\hline Diarrhea & 33.3 & Febrile neutropenia & 20 & Cardiac complications & 16.7 & Renal insufficiency & 20 \\
\hline Anemia & 16.7 & Renal insufficiency & 20 & Febrile neutropenia & 16.7 & Asthenia & 20 \\
\hline Afebrile neutropenia & 16.7 & Infection & 20 & Thrombocytopenia & 16.7 & & \\
\hline Febrile neutropenia & 16.7 & & & Asthenia & 16.7 &
\end{tabular}


Table 3. The adverse events that most impact QoL and treatment adherence during MM treatment in both healthcare systems, based on the physicians' response rate

\begin{tabular}{lcccc}
\hline & \multicolumn{2}{c}{ Quality of Life (\%) } & \multicolumn{2}{c}{ Adherence (\%) } \\
\cline { 2 - 5 } & Public & Private & Public & Private \\
\hline Peripheral neuropathy & 66.7 & 80 & 66.7 & 80 \\
\hline Kidney failure & 50.0 & 20 & - & 20 \\
\hline Asthenia & 50.0 & 40 & 66.7 & 20 \\
\hline Infection & 50.0 & 40 & 33.3 & 40 \\
\hline Afebrile neutropenia & 33.3 & 20 & - & 20 \\
\hline Diarrhea & 33.3 & 40 & 66.7 & 20 \\
\hline Anemia & 16.7 & 20 & - & - \\
\hline Thrombocytopenia & 16.7 & - & - & - \\
\hline Nausea/ vomiting & 16.7 & - & 16.7 & - \\
\hline Febrile neutropenia & - & 20 & - & 20 \\
\hline
\end{tabular}

Table 4. The main differences between oral and intravenous therapies in QoL on both healthcare systems, based on physicians' response rate

\begin{tabular}{lcc}
\hline & Public & Private \\
\hline $\begin{array}{l}\text { Oral therapy has less impact on the } \\
\text { routine / daily activities of the patient }\end{array}$ & $60 \%$ & $100 \%$ \\
\hline $\begin{array}{l}\text { Oral therapy is usually superior } \\
\text { in controlling symptoms }\end{array}$ & $20 \%$ & - \\
\hline $\begin{array}{l}\text { Oral therapy is usually associated with } \\
\text { the patient's better emotional state }\end{array}$ & $20 \%$ & $25 \%$ \\
\hline $\begin{array}{l}\text { Increased difficulty in properly } \\
\text { administering oral therapy }\end{array}$ & $20 \%$ & - \\
\hline $\begin{array}{l}\text { Intravenous therapy is usually } \\
\text { associated with increased toxicity }\end{array}$ & - & $50 \%$ \\
\hline
\end{tabular}

Table 5. The main differences between oral and intravenous therapies in Adherence on both healthcare systems, based on physicians' response rate

\begin{tabular}{lll}
\hline & Public & Private \\
\hline $\begin{array}{l}\text { Higher adherence to oral therapy due to } \\
\text { lower impairment (or greater gain) to QoL }\end{array}$ & $66.7 \%$ & $100 \%$ \\
\hline $\begin{array}{l}\text { Increased adherence to oral therapy } \\
\text { by causing fewer/milder AEs }\end{array}$ & $33.3 \%$ & $66.7 \%$ \\
\hline $\begin{array}{l}\text { Greater adherence to intravenous therapy } \\
\text { because it was administered at the } \\
\text { hospital/center on a scheduled date }\end{array}$ & $33.3 \%$ & - \\
\hline $\begin{array}{l}\text { Increased adherence to oral therapy } \\
\text { for patient convenience }\end{array}$ & - & $33.3 \%$ \\
\hline
\end{tabular}

*AE: Adverse event; QoL: Quality of Life

\section{Discussion}

Through this study based on expert opinions, we were able to describe information regarding MM patients' profile, their unmet medical needs and barriers for the diagnosis and
Table 6. The distribution of image exams used on each step in both healthcare systems, based on the physicians' response rate

\begin{tabular}{lcccccccc}
\hline & \multicolumn{4}{c}{ Public (\%) } & \multicolumn{4}{c}{ Private (\%) } \\
\cline { 2 - 9 } & X-ray & NMR & CT & PET & X-ray & NMR & CT & PET \\
\hline Diagnosis & 66.7 & 50.0 & - & - & 60 & 60 & - & - \\
\hline Follow-up & 33.3 & 50.0 & 33.3 & - & 20 & 60 & 20 & 20 \\
\hline
\end{tabular}

treatment of MM in Brazil, according to specialist's point of view. We successfully collected information, through a questionnaire and a panel discussion, from seven highly experienced physicians in the management of MM, with more than 18 years of experience. Most participants work in both the public and private healthcare systems.

As reported, there is a wide range in the number of patients treated by each physician. During the panel discussion, the participants explained that the higher numbers of patients are related to the high volume of patients in the public hospitals. Despite regionalization of treatment according to patients' address, the patients search for better treatment conditions in reference hospitals from different regions, especially in the Southeast Region. Another topic mentioned by the participants was the number of remote appointments in reference hospitals. Occasionally, physicians from different regions make remote appointments in reference hospitals for a second opinion about patients' diagnosis and treatments.

Compared to other cancers, MM is relatively rare with an estimated incidence of four new cases per 100,000 in the United States (Rajkumar 2016). In Brazil, data on MM incidence is unverified. Also, MM presents non-specific symptoms that may include back pain and anemia, among others. Because of this, one of the main challenges over MM is related to its diagnosis. In MM, delayed diagnosis increase disease complications, with a significant impact in disease-free survival analysis (Kariyawasan et al. 2007). According to the results of this study panel, general practitioners are the most common specialty referring MM patients, particularly in the public healthcare system, referring more than half of the patients. This may be related to the non-specific symptoms, with the patient visiting the primary care practitioners at a local level, initially, and then being referred to a specialist. In the private sector, there is a smaller share of general practitioners, with many patients being referred from other specialties than general practitioners. This may be explained by the greater availability of professionals from different specialties in the private sector. For instance, as the participants mentioned, many patients are referred from geriatricians, one specialty that is not much available in the public sector.

Our results also showed a higher proportion of patients in ISS stages II and III at diagnosis, corroborating data pre- 
viously published in Brazilian and Latin American scenarios (Hungria et al. 2008, Hungria et al. 2017). The late-stage MM may be another indicator of a delayed diagnosis process. As mentioned before, the patients tend to visit physicians from different specialties and receive treatments for other conditions until they are diagnosed correctly with MM. Additionally, a delay in MM diagnosis could extend to one year in some cases (Kariyawasan et al. 2007, Friese et al. 2009). Likewise, many patients tend to wait until the worsening of symptoms to visit their physicians, so the delay in MM diagnosis seems not only to be related to healthcare system issues but also to a delay in patients seeking medical assistance (Kariyawasan et al. 2007).

In the public health system, delayed diagnosis may be aggravated due to limited access to diagnostic procedures. Ultimately, the lack of access to some diagnostic tests, combined the delay of patients seeking medical assistance and delayed MM diagnosis by non-specialist physicians, negatively impacts time-to-diagnosis and, consequently, on patients' prognosis.

In the last decades, several advances in the treatment of MM were achieved, which resulted in the increased overall survival rates of MM patients. Therefore, MM is becoming a long-lasting disease, getting closer to the concept of a chronic disease. As a result, more attention is being given to patients' QoL. All the participants in this study considered of most importance the use of tools to evaluate the QoL of MM patients in clinical practice. For instance, MM patients face many symptoms that affect QoL such as pain, fatigue, and peripheral neuropathy, among others, during and after the treatment (Ramsenthaler et al. 2016), indicating the importance of managing patients' QoL. The majority of participants mentioned that QoL is currently used to define therapy in most cases, but, in some cases, it is still conditioned to the resources available in the institution. This barrier reflects the difficulty of applying statistically significant changes in QoL to clinical practice (Kvam and Waage 2015). This lack of consensus hinders the use of such tools to determine the therapy strategies. Besides, participants reported that QoL questionnaires should be adapted to the clinical practice, as they require more time and a multi-professional team, which is not always possible. The scenario of lack of infrastructure to apply the QoL tools in daily routine also represents a barrier.

Based on the results obtained, peripheral neuropathy was the most common AE in MM/RR patients in both healthcare systems. Moreover, it was also considered the AE with the highest impact on patients' QoL and adherence to treatment. Peripheral neuropathies affect sensory nerves, resulting in symptoms like paresthesia, burning sensation, and loss of response to external stimuli, among others (Dimopoulos et al. 2013), interfering in patients' QoL and their adherence to treatment. Peripheral neuropathy may be related to drugs used in both healthcare systems, mainly thalidomide, which is closely related to this adverse event (Palumbo and Mina 2013, Aguiar et al. 2017). Participants also mentioned that the characteristics of AEs from the public and private sectors might be related to the stage of the disease and the type of therapy patients are receiving. Naturally, it is expected that AEs with higher impact on patients' QoL will also negatively affect patients' adherence to treatment.

Most participants reported that the oral drug administration has a higher positive impact on patients' QoL. The main reasons mentioned for both healthcare systems were the reduced impact on patients' daily activities, improved emotional status of the patients, ease of controlling symptoms and reduced toxicity. These findings corroborate previously published studies that describe oral therapies' improvement in QoL, with an increase in patients' autonomy and improvement in the management of adverse events (Kumar et al. 2017). Despite the positive impact in patients' QoL, oral anti-cancer therapies are usually related to a lack of adherence, as demonstrated previously. (Seal et al. 2016) The patients' adherence to oral anti-cancer therapies is a complex issue and may be threatened by several factors, such as limited financial or social resources, lack of family support, and patient's age, among others (Kurtin et al. 2016). For instance, the participants also mentioned that, especially in the public sector, the low educational level and socioeconomic restrictions of the patients interferes with their adherence to oral anticancer therapies.

This study panel presents some limitations. One of the limitations is the representativeness of the selected participants. The survey and panel discussion comprised of only seven participants. Although representing three out of the five Brazilian regions, the distribution of the sample was limited and did not cover the entire Brazilian territory. Moreover, the results obtained from the questionnaire and discussion only reflect the physicians' expert opinion. Therefore, it could affect the certainty of the values and should not be over-generalized. Nevertheless, the study had an exploratory objective, and further evidence should be generated to clarify the unmet medical needs of MM patients in Brazil.

In summary, this exploratory study showed that there are several challenges about the unmet medical needs related to the diagnosis and treatment of MM in Brazil. According to the participants, guaranteeing access to basic diagnostic procedures, training healthcare professionals on this topic, and improving the knowledge of the general population about the disease would probably help to minimize the barriers for diagnosis and treatment of MM in the Brazilian scenario and may impact QoL and survival expectancies. 


\section{References}

Aguiar, P. M., T. de Mendonca Lima, G. W. B. Colleoni and S. Storpirtis (2017). "Efficacy and safety of bortezomib, thalidomide, and lenalidomide in multiple myeloma: An overview of systematic reviews with metaanalyses." Crit Rev Oncol Hematol 113: 195-212.

Dimopoulos, M. A., M. Beksac, L. Benboubker, H. Roddie, N. Allietta, E. Broer, C. Couturier, M. A. Mazier, R. Angermund and T. Facon (2013). "Phase II study of bortezomib-dexamethasone alone or with added cyclophosphamide or lenalidomide for sub-optimal response as second-line treatment for patients with multiple myeloma." Haematologica 98(8): 1264-1272.

Friese, C. R., G. A. Abel, L. S. Magazu, B. A. Neville, L. C. Richardson and C. C. Earle (2009). "Diagnostic delay and complications for older adults with multiple myeloma." Leuk Lymphoma 50(3): 392-400.

GLOBOCAN. (2012). "GLOBOCAN 2012: Estimated Cancer Incidence, Mortality and Prevalence Worldwide in 2012." Retrieved 13/06/17, 2017, from http://globocan.iarc.fr/Pages/bar_sex_site_prev_sel.aspx.

Hungria, V. T., A. Maiolino, G. Martinez, G. W. Colleoni, E. O. Coelho, L. Rocha, R. Nunes, R. Bittencourt, L. C. Oliveira, R. M. Faria, R. Pasquini, S. M. Magalhaes, C. A. Souza, J. V. Pinto Neto, L. Barreto, E. Andrade, S. Portella Mdo, V. Bolejack, B. G. Durie and A. International Myeloma Working Group Latin (2008). "Confirmation of the utility of the International Staging System and identification of a unique pattern of disease in Brazilian patients with multiple myeloma." Haematologica 93(5): 791-792.

Hungria, V. T., A. Maiolino, G. Martinez, G. O. Duarte, R. Bittencourt, L. Peters, G. Colleoni, L. C. Oliveira, E. Crusoe, E. O. Coelho, R. Pasquini, S. M. Magalhaes, R. Nunes, J. V. Neto, R. M. Faria, M. Souza, N. Hamerschlak, D. Flantl, J. R. Navarro, G. Conte, D. Gomez-Almaguer, G. Ruiz-Arguelles, B. G. Durie and A. International Myeloma Working Group Latin (2017). "Observational study of multiple myeloma in Latin America." Ann Hematol 96(1): 65-72.

Jordan, K., I. Proskorovsky, P. Lewis, J. Ishak, K. Payne, N. Lordan, C. Kyriakou, C. D. Williams, S. Peters and F. E. Davies (2014). "Effect of general symptom level, specific adverse events, treatment patterns, and patient characteristics on health-related quality of life in patients with multiple myeloma: Results of a European, multicenter cohort study." Support Care Cancer 22(2): 417-426.

Kariyawasan, C. C., D. A. Hughes, M. M. Jayatillake and A. B. Mehta (2007). "Multiple myeloma: Causes and consequences of delay in diagnosis." QJM 100(10): 635-640.

Kristinsson, S. Y., O. Landgren, P. W. Dickman, A. R. Derolf and M. Bjorkholm (2007). "Patterns of survival in multiple myeloma: A population-based study of patients diagnosed in Sweden from 1973 to 2003." J Clin Oncol 25(15): 1993-1999.
Kumar, S. K., S. V. Rajkumar, A. Dispenzieri, M. Q. Lacy, S. R. Hayman, F. K. Buadi, S. R. Zeldenrust, D. Dingli, S. J. Russell, J. A. Lust, P. R. Greipp, R. A. Kyle and M. A. Gertz (2008). "Improved survival in multiple myeloma and the impact of novel therapies." Blood 111(5): 2516-2520.

Kumar, S. K., R. Vij, S. J. Noga, D. Berg, L. Brent, L. Dollar and A. Chari (2017). "Treating Multiple Myeloma Patients With Oral Therapies." Clin Lymphoma Myeloma Leuk 17(5): 243-251.

Kurtin, S., K. Colson, J. D. Tariman, B. Faiman and E. Finley-Oliver (2016). "Adherence, Persistence, and Treatment Fatigue in Multiple Myeloma." Journal of the Advanced Practitioner in Oncology 7(1): 71-77.

Kvam, A. K. and A. Waage (2015). "Health-related quality of life in patients with multiple myeloma—does it matter?" Haematologica 100(6): 704-705.

Kyle, R. A. and S. V. Rajkumar (2009). "Criteria for diagnosis, staging, risk stratification and response assessment of multiple myeloma." Leukemia 23(1): $3-9$

Larocca, A. and A. Palumbo (2011). "Evolving paradigms in the treatment of newly diagnosed multiple myeloma." J Natl Compr Canc Netw 9(10): 1186-1196.

Palumbo, A. and R. Mina (2013). "Management of older adults with multiple myeloma." Blood Rev 27(3): 133-142.

Raje, N., B. Faiman, R. D. Harvey, S. E. Kurtin, S. Lonial, S. K. Kumar, A. D. Cohen, M. A. Conde, S. A. Giralt, M. S. Recine, E. R. Tombler, E. Stadtmauer, S. Jagannath, K. C. Anderson and G. Managing Myeloma Continuing Education Initiative Advisory (2014). "Identifying professional education gaps and barriers in multiple myeloma patient care: Findings of the Managing Myeloma Continuing Educational Initiative Advisory Committee." Clin Lymphoma Myeloma Leuk 14(5): 356-369.

Rajkumar, S. V. (2016). "Multiple myeloma: 2016 update on diagnosis, riskstratification, and management." Am J Hematol 91(7): 719-734.

Ramsenthaler, C., T. R. Osborne, W. Gao, R. J. Siegert, P. M. Edmonds, S. A. Schey and I. J. Higginson (2016). "The impact of disease-related symptoms and palliative care concerns on health-related quality of life in multiple myeloma: A multi-centre study." BMC Cancer 16: 427.

Seal, B. S., S. Anderson and K. M. Shermock (2016). "Factors Associated with Adherence Rates for Oral and Intravenous Anticancer Therapy in Commercially Insured Patients with Metastatic Colon Cancer." J Manag Care Spec Pharm 22(3): 227-235.

Spicka, I. (2014). "Advances in multiple myeloma therapy during two past decades." Comput Struct Biotechnol J 10(16): 38-40.

Torre, L. A., A. M. Sauer, M. S. Chen, Jr., M. Kagawa-Singer, A. Jemal and R. L. Siegel (2016). "Cancer statistics for Asian Americans, Native Hawaiians, and Pacific Islanders, 2016: Converging incidence in males and females." CA Cancer J Clin 66(3): 182-202. 